\title{
Flammability of Benzoxazine Resin Based Carbon Fibre Composite Samples
}

\author{
Parth Lal, Gajaraj Gajapathi, Raguraman Munusamy* \\ Department of Mechanical Engineering, Indian Institute of Information Technology Design and Manufacturing, \\ Kancheepuram, Chennai 600127, India
}

Corresponding Author Email: raguraman.munusamy@iiitdm.ac.in

https://doi.org/10.18280/rcma.303-410

Received: 12 April 2020

Accepted: 28 July 2020

\section{Keywords:}

flammability retardancy, CFRP composite, carbon fibre, benzoxazine resin, UL94

\begin{abstract}
The present paper is dealing with the flammability characteristics of a composite system manufactured with hybrid benzoxazine resin and carbon fibre. Benzoxazine thermoset resin can polymerize on heating to $200^{\circ} \mathrm{C}$ to give a good thermal resistance, high mechanical strength properties and good processability with nil volatiles and near-zero volume change during cure. Benzoxazine resin possesses excellent flammability behavior which is similar to phenolic resins due to its nature of formation of a comparable network after polymerization. Samples were made using bi-directional 2x2 twill of 200 GSM carbon fibres with Anabond®Anazine 1951 hot cured hybrid benzoxazine monomer resin. Samples were cut and tested as per UL94 vertical burning standard using a Bunsen burner apparatus. It is observed from the test results that the samples can extinguish fire within 3 seconds after first flame application and 4 seconds after second flame application; this fulfills the requirement for UL94 V0 fire retardancy classification which is the mandated requirement for the composite materials used in spacecraft and aerospace applications.
\end{abstract}

\section{INTRODUCTION}

The composite industry is exponentially growing with its incorporation in various structural applications including automotive, railways, transport, aviation, building, marine, military and space sectors due to its exceptional stiffness, high strength to weight ratio, resistance to fatigue, impact and blast loads [1-4]. The strength and stiffness requirements were met by the composite industries; however, achieving of fire retardant behavior for the same composite materials has become a great challenge due to the criteria set by the regulation agencies like FAA/EASA etc.

Researchers have tried a variety of combinations of resin and filler additives for meeting flammability standards. The filler additives are mainly divided into two groups: (i) halogenated like bromine and chlorine and (ii) nonhalogenated such as aluminium hydroxide, magnesium hydroxide, antimony oxide, organo-phosphorous compounds and nitrogen based compound, and intumescent systems. Halogen based additives were actively used to enhance the fire resistance of composite systems; however, it has been banned due to its adverse effects including toxic smokes, health, and environmentally hazardous nature. Laachachi et al. [5] have studied the fire retardant behavior of PMMA material by adding titanium oxide and ferric oxide nanoparticles and observed a reduction in peak heat release in both cases with a better performance exhibited by titanium oxide. Mishra et al. [6] observed $35 \%$ improvement in the fire performance of polypropylene composite on addition of nano-magnesium hydroxide. Toldy et al. [7] investigated the applicability of TEDAP, an organo-phosphorous compound on epoxy and observed excellent flame retardancy with $960^{\circ} \mathrm{C}$ glow wire flammability index and loss of ignition. Shumao et al. [8] treated ramie fibre as well as the poly (lactic acid) (PLA) matrix with ammonium polyphosphate for preparing the composites; it showed UL94 V0 rating for fire retardancy and high temperature thermal protection. Suppakarn et al. [9] and Tai et al. [10] have both studied the effect of magnesium hydroxide on polypropylene based and observed a decreasing burning rate with increasing magnesium hydroxide concentration. Zhao et al. [11] have used a combination of three flame retardant elements; $\mathrm{P}, \mathrm{N}$ and $\mathrm{S}$, on a glass fiber reinforced PET and achieved a UL $94 \mathrm{~V} 0$ rating on $15 \%$ of its addition. Iqbal et al. [12] and Pinto et al. [13] investigated the addition of ATH on epoxy and polyurethane elastomers that achieved UL94-V1 and V2 criteria respectively.

Benzoxazine resin is a new class of thermoset resin that has drawn immense interest in recent decade due to its advantages including low cure shrinkage and improved fire, smoke and toxicity properties, suitable for applications in electronic devices [14], high performance brake adhesives in sports cars [15] and in matrix resins for carbon fiber reinforced materials in the aerospace sector [16]. Tsotra et al. [17] compared the flammability characteristics of two benzoxazine systems developed at Huntsman with the state of the art phenolic resin which is currently being used for aerospace interior systems. It is observed that LMB6498 showed flammability performance within the specifications for both 12 seconds and 60 seconds tests. In contrast to additive filler agents, there have been some works published on benzoxazine achieving ULV0 classification on the incorporation of reactive flame retardants including bromine and phosphorus [18, 19] which are covalently bonded to the benzoxazine polymers. However, they are rather not economical and large amounts of flame 
retardant might alter the physical and mechanical properties of the polymer. Comer et al. [20] manufactured laminates of benzoxazine by liquid resin infusion and compared its mechanical properties against candidates of other thermosetting classes including epoxy and bismaleimide; it is noted that benzoxazine outperformed other resin systems in terms of interlaminar shear strength, flexural strength and toughness.

As observed in the above literature, achieving UL94 V0 fire retardancy classification is challenging without the addition of fire retardant filler agents in the resin. Nevertheless, addition of fillers causes several issues such as change in viscosity, non-uniform dispersion in the resin system, altered curing cycle, non-uniform and deteriorated strength across samples. On the other hand, reactive flame retardants can be expensive, alters the physical and mechanical properties and are at a nascent stage of research. Therefore, this work was aimed at studying the fire retardant behavior of hybrid benzoxazine resin based carbon fibre composites. Novelty of this research lies in a benzoxazine resin system without the addition of any fire retardant agents confirms to a UL94 V0 classification with an average extinguishing time of 3 seconds after first flame application and 4 seconds after second flame application.

\section{MATERIAL AND METHOD}

A bi-directional $2 \times 2$ carbon fibre twill of $200 \mathrm{gsm}$, Bhor Force®TC200 was employed to lay-up composite laminates. This carbon fibre possesses a tensile strength of $4000 \mathrm{MPa}$ and a tensile modulus of $240 \mathrm{GPa}$. Material density of $1.8 \mathrm{~g} / \mathrm{cm}^{3}$, filament diameter of $7 \mu \mathrm{m}$ and elongation of $1.7 \%$ was noted for the carbon fibre from the technical sheet provided by the manufacturer, BHOR. A commercial grade of hybrid benzoxazine, Anabond ${ }^{\circledR}$ Anazine 1951-hot cured hybrid benzoxazine monomer resin based on Bisphenol-F and Phenol was employed in this study. Table 1 shows the properties of the uncured resin. This thermoset resin can polymerize on heating to $200^{\circ} \mathrm{C}$ to give good thermal resistance and high mechanical strength properties. This resin has good processability with nil volatiles and near zero volume change during cure; it has also got fire, smoke and toxicity property and has no water absorption. The flammability characteristics of benzoxazine are very similar to the phenolic resins due to the formation of a comparable network created after polymerization $[\mathrm{R}]$.

Table 1. Properties of Anabond $®$ Anazine 1951 resin

\begin{tabular}{ll}
\hline Density, g/cc (ATM R 005) & $1.18-1.22$ \\
\hline $\begin{array}{l}\text { Viscosity at } 100^{\circ} \mathrm{C}(\mathrm{cps}) \\
\text { (Spindle 27, RPM 100, ATM R 006) }\end{array}$ & $400-2000$ \\
\hline Moisture content, \% (ATM R 011) & $<1.0$ \\
\hline Gel time $\left(220^{\circ} \mathrm{C}\right)$, seconds & 960 \\
\hline Curing temp, DSC, ${ }^{\circ} \mathrm{C}$ & 227 \\
\hline Tg ${ }^{\circ} \mathrm{C}$ by DSC & 155 \\
\hline
\end{tabular}

The amount of resin (trade name as Anabond $\AA$ Anazine 1951) has been chosen as 60:40 fiber/resin weight ratio which is equivalent to a fiber/resin volume ratio of 50:50. The fiber/resin volume ratio has been calculated using relation Eq. (1).

$$
\frac{V_{\text {fiber }}}{V_{\text {resin }}}=\left(\frac{W_{\text {fiber }}}{W_{\text {resin }}}\right) *\left(\frac{\rho_{\text {fiber }}}{\rho_{\text {resin }}}\right)
$$

where, $V_{\text {fiber }}$ is fibre volume, $V_{\text {resin }}$ is resin volume, $W_{\text {fiber }}$ is fibre weight, $W_{\text {resin }}$ is resin weight, $\rho_{\text {fibre }}$ is fiber density and $\rho_{\text {resin }}$ is resin density. Samples were initially made for three different fiber/resin volume ratios such as $40 \%, 50 \%$ and $60 \%$; tensile strength of these composites indicated an increasing trend and showed early signs of delamination beyond $50 \%$ of fiber/resin volume ratio. This observation is consistent with the research performed by Swapnil et al. [21].

The selected carbon fibre cloth was used for making a five layered laminate and cut for a dimensional requirement of 165 $\mathrm{mm} \times 165 \mathrm{~mm}$ that weighed $50 \mathrm{~g}$ as shown in Figure 1. The amount of resin required for each laminate was computed based on a 60:40 fibre/resin weight ratio and then it was diluted by adding enough acetone solvent to increase the viscosity for better wettability and uniform application of the resin onto the fibre as shown in Figure 2. The evaporation of the solvent in the fibre resin system was carried out by keeping the wet laminate into an oven at $80^{\circ} \mathrm{C}$ for 30 mins. A constant contact pressure of about $20 \mathrm{~kg} / \mathrm{cm}^{2}$ was applied at room temperature for 5 mins using a hot press to ensure the stacked prepreg are tightly aligned and formed. Curing cycle starts with heating the laminate in an incremental manner to $160^{\circ} \mathrm{C}$ as given in Table 2 whilst constant pressure of $20 \mathrm{~kg} / \mathrm{cm}^{2}$ is applied and then the laminate was kept in the oven at $200^{\circ} \mathrm{C}$ for 2 hours for post-curing. The final CFRP laminate manufactured using this process is as shown in Figure 2.
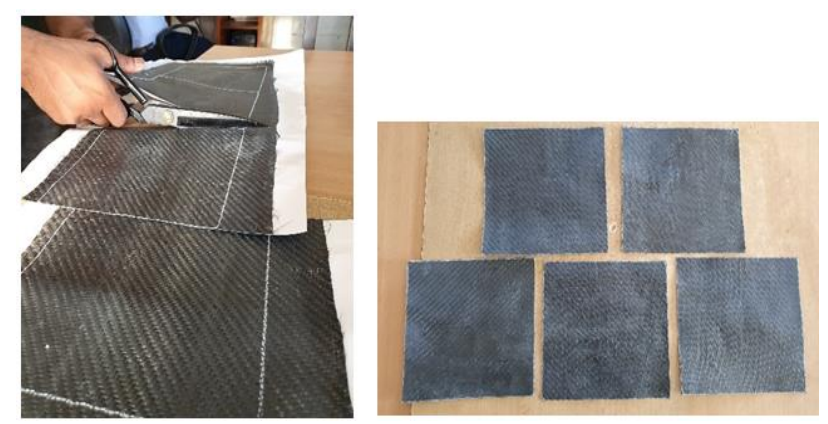

Figure 1. Carbon cloth cut for $165 \mathrm{~mm} \times 165 \mathrm{~mm}$ dimension
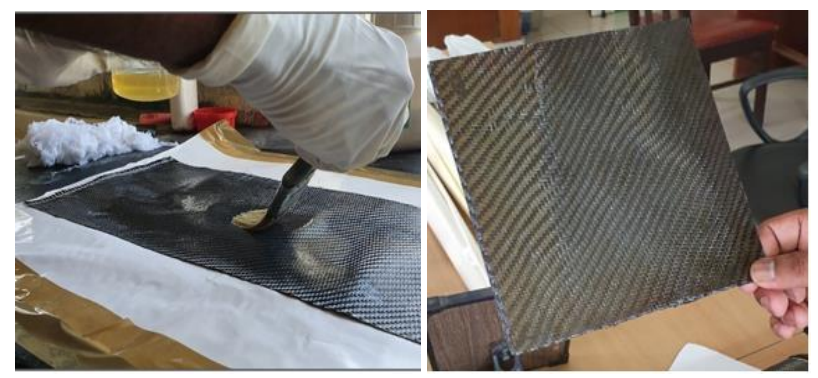

Figure 2. Application of diluted benzoxazine resin onto the carbon fibre cloth and the final laminate made

Table 2. Temperature increments for hot pressing

\begin{tabular}{cccc}
\hline $100^{\circ} \mathrm{C}$ & $120^{\circ} \mathrm{C}$ & $150^{\circ} \mathrm{C}$ & $160^{\circ} \mathrm{C}$ \\
\hline 10 mins & 10 mins & 120 mins & 45 mins \\
\hline
\end{tabular}

Flammability characteristics of the composite system have to be evaluated by conducting UL94 tests. UL94 is a standard for the safety of the flammability of plastic material in devices and appliances. This standard determines the material's tendency to either extinguish or spread the flame once the specimen is ignited. UL94 contains the following tests: 94HB, 
94V, 94VTM, 94-5V, 94HBF, 94HF and radiant panel. The 94HB test describes the horizontal burn method whilst 94V and 94VTM are used for vertical burn which is a more stringent test than $94 \mathrm{HB}$. The $94-5 \mathrm{~V}$ test is for enclosures for products that are not easily moved or are attached to a conduit system. The $94 \mathrm{HBF}$ and HF are used for nonstructural foam materials like acoustical foam. Radiant panel test is used to determine the flame spread of a material that may be exposed to fire. The $94 \mathrm{~V}$ test was employed in which the test specimen is to be held vertically whilst the burner is placed at $45^{\circ}$ as shown in Figure 3. The blue flame should be applied to the specimen for up to 10 seconds for the test specimen to burn and then left for extinguishing the fire. This process is repeated twice and the afterflame time is recorded. The recorded time should be compared against the standard as tabulated in Table 3 for fire retardancy classification.

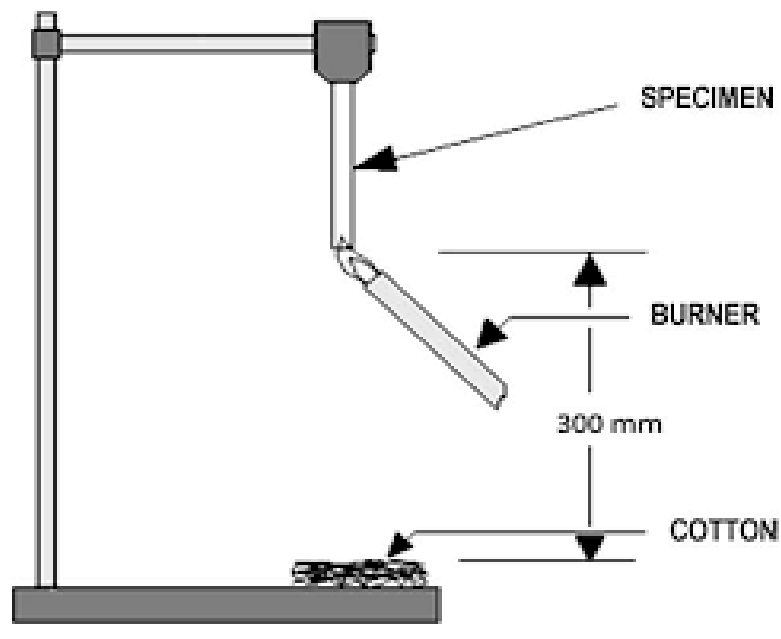

Figure 3. UL 94 test apparatus

Ratings, V0, V1 and V2 indicate that the material has to be tested in a vertical position and self-extinguished within a specified time after the ignition source was removed as per detailed in Table 3. The vertical ratings also indicate whether the test specimen dripped flaming particles that ignited a cotton indicator located below the sample. The afterflame time, $\mathrm{t}_{1}$ indicates the time taken by the sample to self-extinguish after the first flame application. Immediately after the flame ceases, the burner is again placed for the second flame application for the specified time and the afterflame time, $t_{2}$ is calculated.

The specimen is clamped from the upper $6 \mathrm{~mm}$ of the specimen, with the longitudinal axis vertical, so that the lower end of the specimen is $300 \pm 10 \mathrm{~mm}$ above the horizontal layer. The methane gas supply to the burner is adjusted to produce a gas flow rate of $105 \mathrm{ml} / \mathrm{min}$ with a back pressure of less than $10 \mathrm{~mm}$ of water. The burner is then adjusted to produce a blue flame with no inner cone $20 \pm 1 \mathrm{~mm}$ high. The time for the temperature to rise from $100 \pm 2^{\circ} \mathrm{C}$ to $700 \pm 3^{\circ} \mathrm{C}$ shall be $44 \pm 2 \mathrm{~s}$. The flame is applied centrally to the middle point of the bottom edge of the specimen so that the top of the burner is $10 \pm 1 \mathrm{~mm}$ below the point of the lower end of the specimen, and is maintained at that distance for $10+0.5$ seconds. If the specimen drips molten or flaming material during the flame application, the burner should be tilted to an angle of $45^{\circ}$ and withdrawn just sufficiently from beneath the specimen to prevent the material from dripping into the barrel while maintaining the $10 \pm 1 \mathrm{~mm}$ spacing. After the application of the flame to the specimen for $10 \pm 0.5$ seconds, the burner is immediately withdrawn at a rate of approximately $300 \mathrm{~mm} / \mathrm{sec}$, to a distance of at least $150 \mathrm{~mm}$ from the specimen and simultaneously the afterflame time, $t_{1}$ is measured in seconds. As soon as the after flaming of the specimen ceases, the burner is placed immediately again according to step 4 and the same procedure is to be followed to measure the afterflame time, $\mathrm{t}_{2}$.

All specimens are to be cut from a sheet material, or molded to the necessary form as shown in Figure 4. After the cutting operation, care must be taken to remove all the dust particles from the surface of the specimen and the cut edges are to have a smooth finish. Standard bar specimens are to be $125 \pm 0.5 \mathrm{~mm}$ wide with maximum thickness not exceeding $13 \mathrm{~mm}$ and radius of corners is not to exceed $1.3 \mathrm{~mm}$. The cut samples for the flammability test are as shown in Figure 4. A total of 10 specimens were tested using the facility available at CIPET, Chennai (Govt. of India organization for testing of materials and polymers). Five samples were tested after conditioning for 48hours at $23^{\circ} \mathrm{C}$ and $50 \% R H$. This is performed so as to make sure that water particles from external sources do not contribute to the flame retardancy.

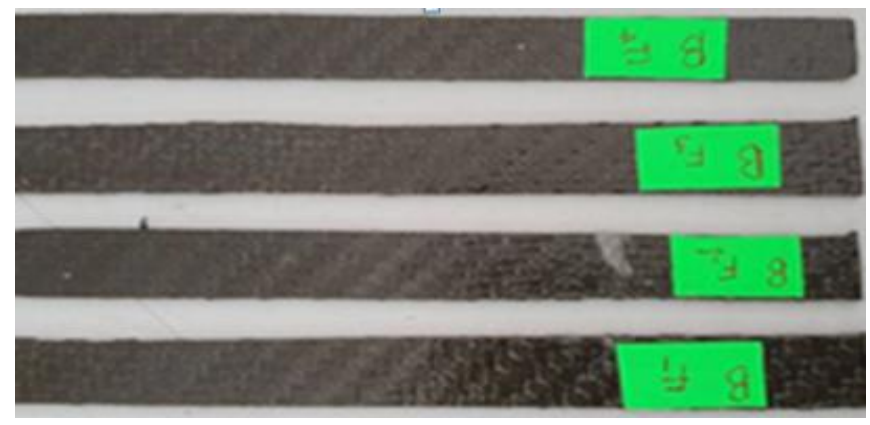

Figure 4. Cut CFRP samples for UL94 fire retardant test

Additionally, tensile test as per ASTM D3039 and flexural test as per ASTM D7264 standards were performed to assess the mechanical behaviour of the developed composite materials. The dimensional requirement for the tensile test specimen and the cut sample for the same is shown in Figure 5(a) and (b) respectively.The tensile tests were conducted by applying a constant strain rate of $1.3 \mathrm{~mm} / \mathrm{min}$ as given in the standard.

Table 3. Vertical burning UL94-V classification criteria

\begin{tabular}{|c|c|c|c|}
\hline Test criteria & V0 & V1 & $\mathbf{V 2}$ \\
\hline Afterflame time for each individual specimen $\mathrm{t}_{1}$ or $\mathrm{t}_{2}$ & $<=10 \mathrm{~s}$ & $<=30 \mathrm{~s}$ & $<=30 \mathrm{~s}$ \\
\hline Total afterflame time for any condition set ( $\mathrm{t}_{1}$ plus $\mathrm{t}_{2}$ for the 5 specimens) & $<=50 \mathrm{~s}$ & $<=250 \mathrm{~s}$ & $<=250 \mathrm{~s}$ \\
\hline Afterflame plus afterglow time for each individual specimen after the second flame application $\left(t_{2}\right.$ plus $\left.t_{3}\right)$ & $<=30 \mathrm{~s}$ & $<=60 \mathrm{~s}$ & $<=60 \mathrm{~s}$ \\
\hline Afterflame or afterglow of any specimen up to the holding clamp & No & No & No \\
\hline Cotton indicator ignited by flaming particles or drops & No & No & Yes \\
\hline
\end{tabular}



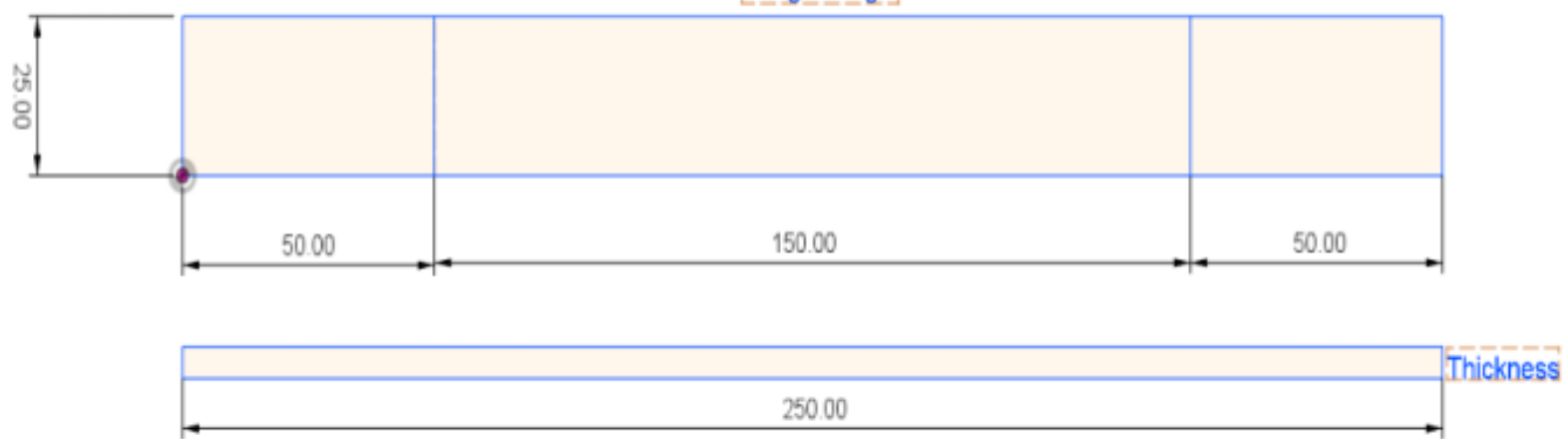

(a) Dimensions as per ASTM D3039 standard

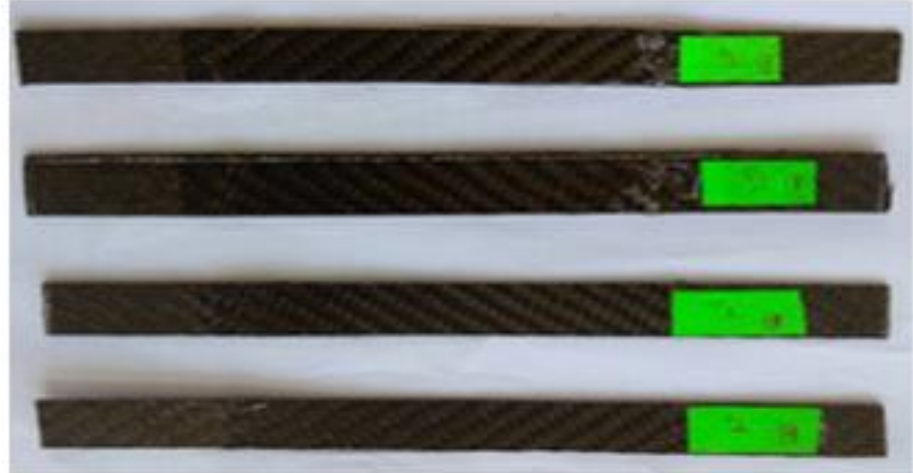

(b) cut sample for tensile test

Figure 5. Tensile specimen dimension and the cut sample

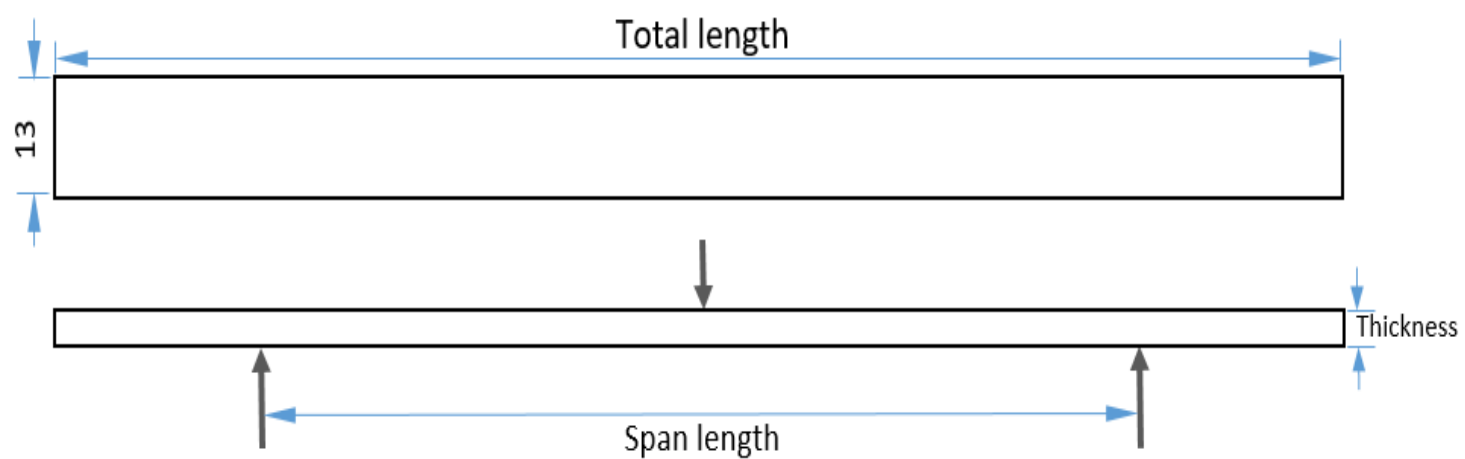

(a) Requirements as per ASTM D3039 standard

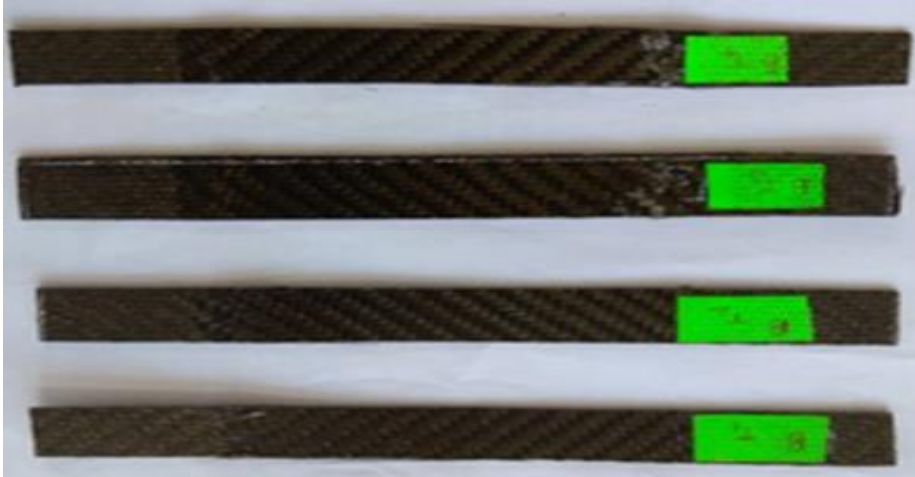

(b) cut sample for flexural test

Figure 6. Flexural test specimen and the cut samples

The flexural test was performed under ASTM D7264 standard which is suitable for polymer matrix composites. This test method has been designed for optimal use with continuous-fibre-reinforced polymer matrix and differs from other flexural methods like D790 and D6276, which includes the chance in span-to-thickness of 32:1 in D7264 whereas other two methods use 16:1.The specimen dimension as described in the ASTM D7264 standard and the cut samples for flexural testing are as shown in Figure 6 (a) and (b). The prepared samples were tested under constant head-speed of $1 \mathrm{~m} / \mathrm{min}$ 
Table 4. After flame time from the Bunsen burner test

\begin{tabular}{ccc}
\hline Sample No & $\begin{array}{c}\left.\text { After flame time after first flame application ( } \mathbf{t}_{1}\right) \text { in } \\
\text { seconds }\end{array}$ & $\begin{array}{c}\text { After flame time after second flame application }\left(\mathbf{t}_{2}\right) \text { in } \\
\text { seconds }\end{array}$ \\
\hline 1 & 1 & 1 \\
2 & 2 & 4 \\
3 & 3 & 4 \\
4 & 2 & 2 \\
5 & 1 & 3 \\
Total time & 9 & 14 \\
$(\mathrm{sec})$ & & \\
\hline
\end{tabular}

\section{RESULTS AND DISCUSSION}

All the test samples were prepared and the test was carried out as per the UL 94 standard. The experimental observations are recorded in Table 4. It is observed from this table that each individual test samples showed an afterflame time way below the required UL94 V0 classification. The summed total afterflame time, $t_{1}$ and $t_{2}$ have been recorded as 9 and 14 seconds respectively which is less than the UL94 V0 classification criteria and no flaming particle drips were observed.

Tensile strength of $509 \mathrm{MPa}$ and flexural strength of 487MPa was observed from the respective tests which show better strengths than epoxy resin based carbon fibre composites commonly used in aerospace applications [22]. The snap-shot of the testing process and the post-mortem report of the test are shown in Figures 7 and 8. DGM and LIT stand for delamination at gauge middle and lateral inside grip top respectively. Based on the observations of DGM and LIT, all the tests performed are at an acceptable level.
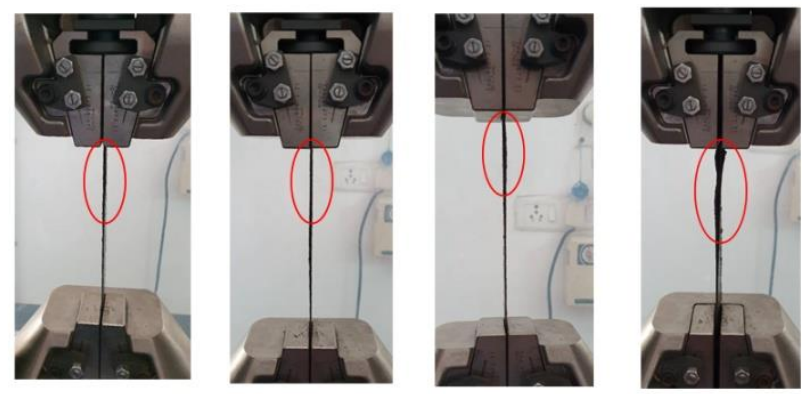

Figure 7. Progressive failure of tensile sample

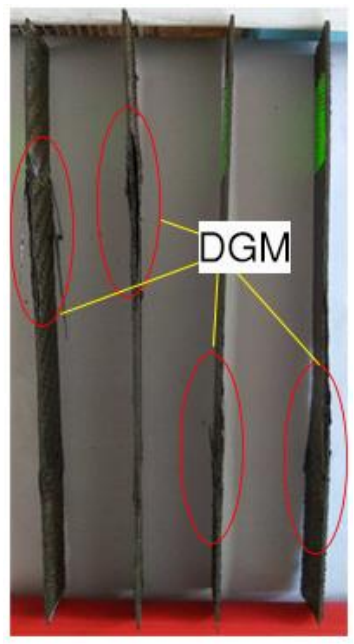

Figure 8. Failed tensile samples

\section{CONCLUSION}

The present paper dealt with the understanding and characterization of carbon fibre with hybrid benzoxazine resin based composite laminate structure on the fire retardance behavior. It is observed from the Bunsen burner test that the samples exhibited UL94 V0 fire retardancy classification. In addition, mechanical properties were analyzed and compared with epoxy-based carbon fibre composites, commonly used in the aerospace applications. The measured tensile and flexural strength was found to be comparable with epoxy based composite system. Therefore, it can be concluded from this study that benzoxazine resin can serve as a desirable alternative resin system for achieving UL94 V0 flammability classification, without compromising on the mechanical properties for structural applications.

\section{ACKNOWLEDGMENT}

The authors would like to express their heartfelt gratitude to $\mathrm{M} / \mathrm{s}$. Fibtec Enterprises, M/s. Anabond and Indian Space Research Organization (ISRO) for their extended support for conducting this research work.

\section{REFERENCES}

[1] Liu, Q., Ou, Z.Y., Mo, Z.W., Li, Q., Du, D.P. (2015). Experimental investigation into dynamic axial impact responses of double hat shaped CFRP tubes. Composites Part B: Engineering, 79: 494-504. https://doi.org/10.1016/j.compositesb.2015.05.016

[2] Xiao, Y., Hu, Y.F., Zhang, J.G., Song, C.S., Huang, X.Y., $\mathrm{Yu}$, J.G., Liu, Z.B. (2018). The bending responses of sandwich panels with aluminium honeycomb core and CFRP skins used in electric vehicle body. Advances in Materials Science and Engineering, 2018: 1-11. https://doi.org/10.1155/2018/5750607

[3] Mines, R.A.W., Tsopanos, S., Shen, Y., Hasan, R., McKown, S.T. (2013). Drop weight impact behavior of sandwich panels with metallic micro lattice cores. International Journal of Impact Engineering, 60: 120-132. https://doi.org/10.1016/j.ijimpeng.2013.04.007

[4] Sutherland, L.S. (2018). A review of impact testing on marine composite materials: Part I - Marine impacts on marine composites. Composite Structures, 118: 197-208. https://doi.org/10.1016/j.compstruct.2017.12.073

[5] Laachachi, A., Cochez, M., Leroy, E., Ferriol, M., Lopez-Cuesta, J.M. (2007). Fire retardant systems in poly (methyl methacrylate): Interaction between metal oxide nanoparticles and phosphinates. Polymer 
Degradation and Stability, 92(1): 61-69. https://doi.org/10.1016/j.polymdegradstab.2006.09.011

[6] Mishra, S., Sonawane, S.H., Singh, R.P., Bendale, A., Patil, K. (2004). Effect of Nano- $\mathrm{Mg}(\mathrm{OH})_{2}$ on the mechanical and flame retarding properties of polypropylene composites. Journal of Applied Polymer Science, 94: 116-122. https://doi.org/10.1002/app.20750

[7] Toldy, A., Szolnoki, B., Marosi, Gy. (2011). Flame retardancy of fibre-reinforced epoxy resin composites for aerospace applications. Polymer Degradation and Stability, $\quad$ 96(3): 371-376. https://doi.org/10.1016/j.polymdegradstab.2010.03.021

[8] Li, S.M., Ren, J., Yuan, H., Yu, T., Yuan, W. (2009). Influence of ammonium polyphosphate on the flame retardancy and mechanical properties of ramie fibrereinforced poly (lactic acid) biocomposites. Polymer International, $\quad 59(2)$ : $242-248$. https://doi.org/10.1002/pi.2715

[9] Suppakarn, N., Kasama, J. (2009). Mechanical properties and flammability of sisal/PP composites: Effect of flame retardant type and content. Composites Part B Engineering, 40(7): 613-618. https://doi.org/10.1016/j.compositesb.2009.04.005

[10] Tai, C.M., Li, K.Y.R. (2001). Mechanical properties of flame retardant filled polypropylene composites. Journal of Applied Polymer Science, 80(14): 2718-2728. https://doi.org/10.1002/app.1386

[11] Zhao, C.S., Huang, F.L., Xiong, W.C., Wang, Y.Z. (2008). A novel halogen-free flame retardant for glassfibre-reinforced poly (ethylene terephthalate). Polymer Degradation and Stability, 93(6): 1188-1193. https://doi.org/10.1016/j.polymdegradstab.2008.03.010

[12] Iqbal, M.A., Iqbal, M.A., Fedel, M. (2018). Fire retardancy of aluminum hydroxide reinforced flame retardant modified epoxy resin composite. Russian Journal of Applied Chemistry, 91: 680-686. https://doi.org/10.1134/S1070427218040225

[13] Pintoa, U.A., Viscontea, L.L.Y., Gallob, J., Nunes, R.C.R. (2000). Flame retardancy in thermoplastic polyurethane elastomers (TPU) with mica and aluminum trihydrate (ATH). Polymer Degradation and Stability, 69(3): 257-260. https://doi.org/10.1016/S01413910(00)00047-1

[14] Rimdusit, S., Ishida, H. (2000). Development of new class of electronic packaging materials based on ternary systems of benzoxazine, epoxy, and phenolic resins. Polymer, 41(22): https://doi.org/10.1016/S0032-3861(00)00164-6
[15] Ishida, H. (2011). Handbook of Benzoxazine Resins. 1st Edition: Elsevier, 605-608.

[16] Rimdusit, S., Jongvisuttisun, P., Jubsilp, C., Tanthapanichakoon, W. (2009). Highly processable ternary systems based on benzoxazine, epoxy, and phenolic resins for carbon fiber composite processing. Journal of Applied Polymer Science, 111(3): 1225-1234. https://doi.org/10.1002/app.29085

[17] Tsotra, P., Setiabudi, F., Weidmann, U. (2008). Benzoxazine chemistry: A new material to meet fire retardant challenges of aerospace interior applications. Engineering, Corpus ID: 18422389.

[18] Li, S.F., Huang, W.D., Liu, X.L., Yu, X., Xiao, W.S. (2010). Synthesis, characterization, and polymerization of brominated benzoxazine monomers and thermal stability/flame retardance of the polymers generated. Polymers for Advanced Technologies, 21(4): 229-234. https://doi.org/10.1002/pat.1418

[19] Lin, C.H., Cai, S.X., Leu, T.S., Hwang, T.Y., Lee, H.H. (2006). Synthesis and properties of flame-retardant benzoxazine by three approaches. Journal of Polymer Science Part A: Polymer Chemistry, 44(11): 3454-3468. https://doi.org/10.1002/pola.21454

[20] Comer, A.J., Dipa, R., Winifred, O., Gearoid, C., Inga, R., Walter, F.S. (2014). OOA (Out of Autoclave) manufacturing of benzoxazine resin systems by LRI (Liquid Resin Infusion) for ambient and high temperature aerospace applications. 35th International Technical Conference \& Forum, Porte deVersaille.

[21] Swapnil, S.A., Sandip, S.B., Chaudhari Bapu, P., Vishal, J.S. (2017). Experimental investigation of mechanical properties of glass fiber/epoxy composites with variable volume fraction. Materials Today: Proceedings, 4(9): 9487-9490. https://doi.org/10.1016/j.matpr.2017.06.209

[22] Rahmani, H., Najafi, S.H.M., Ashori, A. (2014). Mechanical performance of epoxy/carbon fibre laminated composites. Journal of Reinforced Plastics and Composites, 33(8): 733-740. https://doi.org/10.1177\%2F0731684413518255

\section{NOMENCLATURE}

Tg Glass transition temperature, ${ }^{\circ} \mathrm{C}^{-1}$

RH Relative Humidity, dimensionless

$V \quad$ Volume, $\mathrm{m}^{-3}$

$W \quad$ Weight, $\mathrm{kg}$

$\rho \quad$ Density, $\mathrm{kg} \cdot \mathrm{m}^{-3}$ 